\title{
Primary Cutaneous Diffuse Large B-cell Lymphoma, Leg Type
}

\author{
Naoya Fujita, Yosuke Ono, Azusa Sano and Yuji Tanaka
}

Key words: primary cutaneous diffuse large B-cell lymphoma, skin tumor, clinical picture

(Intern Med 59: 1785, 2020)

(DOI: 10.2169/internalmedicine.4497-20)

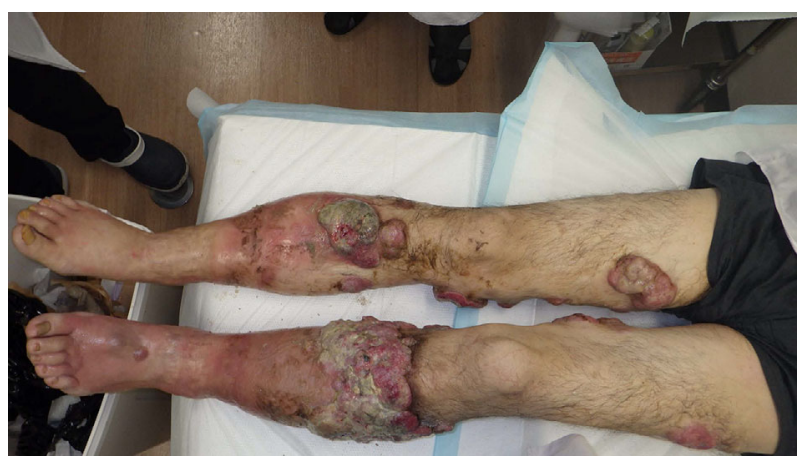

Picture 1.

A 58-year-old man with a history of diabetes mellitus and systemic lupus erythematosus was hospitalized because of multiple rapidly enlarging skin tumors on both legs that were necrotic and foul-smelling (Picture 1). Laboratory studies revealed anemia, hypoalbuminemia, a strong inflammatory response, and a high soluble interleukin-2 receptor concentration [8,400 IU/mL (normal range, 150-520)]. Computed tomography of the chest, abdomen, and pelvis did not reveal any enlarged lymph nodes. Biopsy of a tumor on the left leg revealed diffuse large B-cell lymphoma (DLBCL). Thus, a clinical diagnosis of primary cutaneous DLBCL, leg type, was made. Combination chemotherapy (rituximab, etoposide, prednisone, vincristine, cyclophosphamide, doxorubicin, cytarabine, and methotrexate) administered after

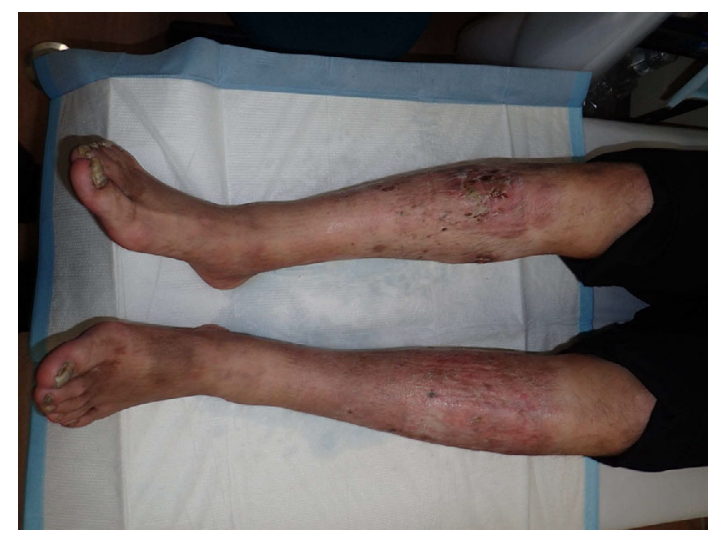

Picture 2.

the failure of first-line therapy resulted in regression of the tumors on both legs at 7 months after the initiation of this second-line chemotherapy (Picture 2). However, at 17 months after the diagnosis, the patient died of respiratory failure due to a massive hemorrhagic pleural effusion with tumor recurrence.

The authors state that they have no Conflict of Interest (COI).

The Internal Medicine is an Open Access journal distributed under the Creative Commons Attribution-NonCommercial-NoDerivatives 4.0 International License. To view the details of this license, please visit (https://creativecommons.org/licenses/ by-nc-nd/4.0/). 